\title{
Geo-Referenced Technical Papers and Journal Articles: A New ASMR Benefit ${ }^{1}$
}

\begin{abstract}
James J. Gusek ${ }^{2}$
Abstract. The American Society of Mining and Reclamation (ASMR) has been publishing proceedings of its annual conferences for almost three decades and it initiated the publication of a journal in 2012. Data related to much of the earlier technical work associated with specific mine sites or localities in the USA and internationally was at risk of being lost or ignored by researchers and remediation practitioners because the paper/journal article titles or keywords of these papers typically lacked a geographic reference. Also, the mine site/location may have been considered confidential at the time the paper was presented and the passage of time may have lifted that restriction.

To remedy this situation and to acquaint potential new ASMR members with the depth of its current and past members' institutional knowledge, ASMR funded the creation of a set of Google Earth ${ }^{\mathrm{TM}}$ placemarks that can be linked to one or more past ASMR technical papers or journal articles. The project was executed in phases. The first phase addressed ASMR papers in the proceedings from 1988 to 2007. The placemarks will be available to members and non-members in the near future.
\end{abstract}

Additional Key Words: Google Earth Placemarks

\footnotetext{
${ }^{1}$ Paper submitted to JASMR as a report of an activity of ASMR

${ }^{2}$ James J. Gusek, P.E. is a senior engineer with Sovereign Consulting Inc., Lakewood, CO
}

DOI: http://doi.org/10.21000/JASMR17010066 


\section{$\underline{\text { Introduction }}$}

In the "search engine" driven world of the internet circa 2017, the ability to quickly find information related to a specific topic unfettered by "data clutter" is daunting, especially when the information desired is imbedded within the text of a document or image and not in web text or HTML format. When key search information is in the form of geographic references which can vary from physical descriptions to latitude and longitude coordinates, the challenge becomes even greater. For mined land reclamationists and their brethren, searching for case studies and technical information can be lost in the pre-internet paper record which is dwindling as libraries as we now know them are running out of physical space and substituting cyberspace. For those of us who remember hard-paper Dewey Decimal card catalogues, the future can be pretty scary.

The American Society of Mining and Reclamation (ASMR) has been publishing proceedings of its annual conferences for almost three decades and it initiated the publication of a journal in 2012. While all the ASMR proceedings have be rendered into digital, searchable format, data related to much of the earlier technical work associated with specific mine sites or localities in the USA and internationally was at risk of being lost or ignored by researchers and remediation practitioners because the paper/journal articles' titles or keywords typically lacked a geographic reference. Also, the mine site/location may have been considered confidential at the time the paper was presented and the passage of time may have lifted that restriction.

For those with paper copies sitting on library shelves, finding a specific paper within the sometimes-multiple volumes of proceedings could take the better part of a day. Even the advent of flash-drives loaded with digital proceedings didn't help unless the files were copied to a common drive or folder.

Clearly, the geo-referencing of ASMR papers and journal articles in a user-friendly format would increase the accessibility of data available at our fingertips (on the ASMR website) if we only knew the specific title or author or year the paper was presented. To this end, this author started to tabulate papers from ASMR and other conferences in a searchable database and shared them with the greater mine remediation technical community through a company website.

But this paper database still did not fill the geo-referencing data gap. 


\section{Google Earth History}

The Google Earth software was introduced in 2005 after Google acquired Keyhole, Inc. which developed the software EarthViewer 3D that was subsequently renamed Google Earth (Wikipedia, 2017). As any Google Earth user knows, it is a powerful program that superimposes aerial or satellite imagery on a digital elevation model of planet earth. In February, 2009, the historical imagery feature was added to Google Earth. This allowed users to compare current conditions with historic ones. Some locations, such as London, England, have images dating back to World War II available. For those interested, the "KML" extension on Google Earth files stands for "Keyhole Markup Language" and the KMZ extension connotes zipped KML files (Wikipedia, 2017)

To mined land reclamationists, the historical image feature can reveal how a given mine site has changed over time in response to restoration activities and/or the passage of time. In many cases, it is difficult to recognize reclaimed mine sites because they blend so well into the surrounding terrain. While some may consider this the definition of success, to a reclamation researcher or a regulator, the site might drop from the radar and the methods used to reclaim the site would be clearly at risk of being lost.

\section{Google Earth Geo-Referencing of ASMR Papers}

In 2015, the ASMR National Executive Committee approved a project to fill the georeferencing data gaps for almost thirty years of ASMR proceedings. A request for proposal directed to academic institutions was issued in late 2015 with the following work scope:

ASMR is seeking proposals from academic institutions that would employ students (graduate and undergraduate) to:

1. Cross reference each ASMR paper with a geographic location if it has one. If the location is confidential and is generically located (e.g., "southwest USA"), the student will make a reasonable effort (a phone call or email) to the primary author of the paper (if they are alive) to request more information.

2. Team with one or more senior ASMR members who may be retired from active employment but would provide guidance to the students and faculty in contacting primary and secondary authors to obtain additional geographic information for a given paper. ASMR will assist the institution in identifying and recruiting these individuals. 
3. Locate the site(s) in Google Earth ${ }^{\mathrm{TM}}$ and create a unique placemark for each site and subsite referenced in the technical paper or journal article. If a given site is confidential but a general geographic province is known, the student will create one or more "dummy" places for locating such sites. For example, from a given paper it can be determined that the confidential site is located "in the Western USA". The student would create a polygon in Google Earth named "Western USA" and the Placemark for the paper would be anchored there.

4. If a paper cannot be associated with a specific site or a geographic province, the student will assign it to a specific technical topic (see below, in No. 6 [highlighted]).

5. Catalogue/organize the placemarks by state in separate Google Earth folders. Confidential sites in a given region would be organized similarly.

6. Create copies of the placemarks and organize these in separate Google Earth folders specific to the paper topic (e.g., revegetation, geochemistry, soils, forestry, tailings, passive treatment of mine water, etc.). These topics might be selected based on the ASMR conference session in which the paper was presented.

7. Forward the Google Earth placemark folders to the ASMR webmaster.

8. Insert the latitude and longitude values for each paper/abstract into an Excel spreadsheet that ASMR provides.

9. Prepare an ASMR abstract for oral presentation at the next ASMR conference in which the summary findings of the work will be shared with the ASMR membership in a dedicated technical session. A student author/presenter is preferred but not required.

The proceedings were subdivided into three "blocks" of proceedings/articles:

- 1988 to 1997

- 1998 to 2007

- 2008 to 2015 plus ASMR Journal articles from Fall 2012 to 2015

\section{$\underline{\text { Selected Academic Institutions }}$}

Two universities responded to the RFP: Southern Illinois University (SIU) in Carbondale, IL and Saint Francis University (SFU) in Loretto, PA. The student teams were led by Dr. Ruopu Li and Dr. William Strosnider, respectively. SIU was awarded the block of papers from 1988 to 1997 
and SFU was awarded the papers from 1998 to 2007. Both teams submitted their work products by the end of 2016 .

\section{$\underline{\text { Geo-Referenced Papers }}$}

While both institutions fulfilled the intent of the RFP, the way the teams organized the data differed and integrating the two datasets may require further refinement. Descriptions of how each team approached the assignment follow.

\section{$\underline{\text { Southern Illinois University Submittal }}$}

The SIU spreadsheet database contained the following fields:

- ID

- Name

- Year

- Authors
- Title

- Technical Division

- Longitude

- Latitude

The SIU team identified 678 unique placemarks in 1028 papers in the 1988 to 1997 proceedings. If a paper did not contain a geographic reference, it was not included in the spreadsheet. The data associated with Google Earth entries was developed as separate KMZ and KML files organized by technical division and year. Some papers had more than one placemark or place name. One 1994 paper had 24 different placemarks. The papers were categorized into the following technical divisions:

- Ecology

- Education

- Forestry/Wildlife

- Geotechnical Engineering

- Landuse Planning and Design
- Soil Overburden

- Tailings

- Water Management-hydrology

- Water Management-mine water treatment 
Table 1 SIU Typical Entries

\begin{tabular}{clclllcc} 
ID & Name & Year & Authors & Title & $\begin{array}{l}\text { Technical } \\
\text { Division }\end{array}$ & Long. & Lat. \\
\hline 1 & $\begin{array}{l}\text { Ackman and } \\
\text { Jones }-1998\end{array}$ & 1988 & $\begin{array}{l}\text { Terry Ackman, } \\
\text { Richard Jones }\end{array}$ & $\begin{array}{l}\text { Stream sealing to reduce } \\
\text { surface water infiltration into } \\
\text { underground mines }\end{array}$ & $\begin{array}{c}\text { Water } \\
\text { Management- } \\
\text { hydrology }\end{array}$ & -78.9178 & 39.5890 \\
\hline 7 & Boyle -1988 & 1988 & James Boyle & $\begin{array}{l}\text { A program to mine and restore } \\
\text { a forested wetland }\end{array}$ & Ecology & -82.1098 & 28.1673 \\
\hline
\end{tabular}

\section{$\underline{\text { Saint Francis University Submittal }}$}

The SFU effort was more elaborate and its spreadsheet database contained the following fields:

- Latitude

- Longitude

- Name

- Icon Description

- Title:

- Authors:

- Year:
- Place Name:

- Conference:

- Keywords:

- Technical Division:

- Volume/Session:

- Country:

- State
- Page

- Additional Info:

- Icon Color

- Folder

- Color

- Item \#

The SFU team identified 1190 unique placemarks in 1076 papers in the 1998 to 2007 proceedings. Like the SIU dataset of papers, some papers had more than one placemark or place name. The papers were categorized into the following technical divisions:

- Ecology

- Education

- Forestry/Wildlife

- Geotechnical Engineering

- Land use: Planning \& Design

- Soil Overburden

- Tailings

- Water Management \& Mine Water Treatment 


\section{Table 2 SFU Typical Entries}

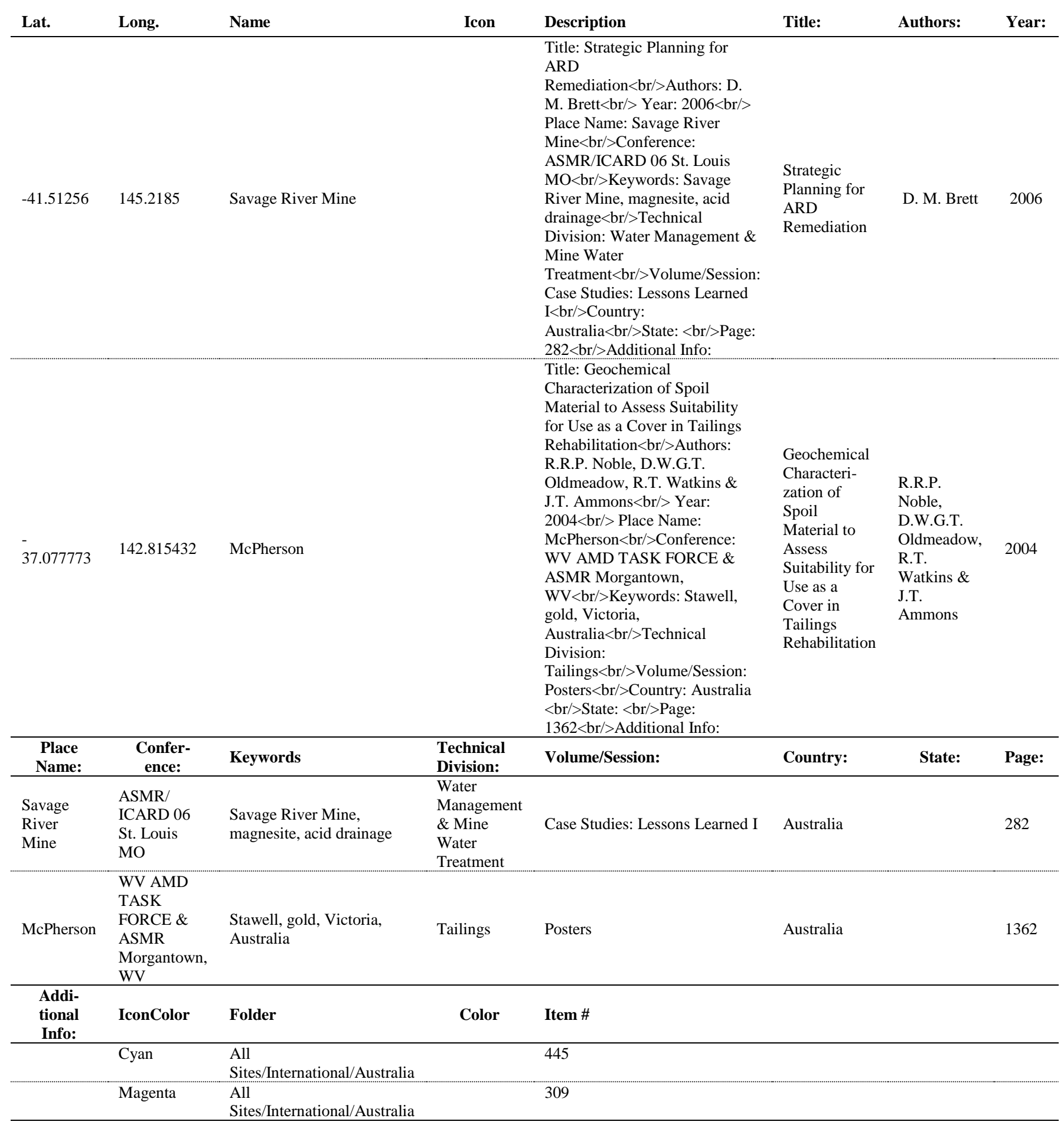




\section{PATH FORWARD}

The block of ASMR papers from 2008 to 2017 and the ASMR Journal articles need georeferencing. Beginning in 2013, manuscripts for ASMR proceedings were not required and only abstracts are available unless authors submitted an ASMR Journal (JASMR) article. It is unlikely that geo-referencing data will be extractable from an abstract alone, so the geo-referencing effort will focus on the JASMR articles moving forward. A policy to include latitude and longitude data as mandatory in JAMSR articles has been adopted.

As one can see, the two sets of geo-referenced papers are quite different in that they contain different amounts of information and are organized differently. On the Google Earth screen, they do not interfere and so they are consequently compatible. Merging the two sets of data may not be necessary and users may desire to keep the two "temporal" blocks of papers separate from a data-management perspective. More and bigger may not necessarily be better.

Distributing the geo-referenced data files to ASMR members will be the next challenge. At the moment, ASMR members may request the data sets "as-is" to beta-test the geo-referenced information. Contact the author. A mechanism for incorporating corrections needs be formalized as well. Each author should try to verify the location(s) in the data sets associated with her or his paper(s).

Eventually, it is envisioned that the data sets might be downloaded from the ASMR website. How this will happen for members versus non-members is being debated; comments and suggestions are welcome and these will likely be managed through a LinkIn discussion group or another social media platform.

\section{References:}

Wikipedia, 2017. https://en.wikipedia.org/wiki/Keyhole_Markup_Language. Accessed 3/27/17. 